\title{
Active Motor Neurons Potentiate Their Own Sensory Inputs via Glutamate-Induced Long-Term Potentiation
}

\author{
Didier Le Ray and Daniel Cattaert \\ Laboratoire Neurobiologie et Mouvements, Centre National de la Recherche Scientifique, 13402 Marseille, \\ Cedex 20, France
}

\begin{abstract}
Adaptive motor control is based mainly on the processing and integration of proprioceptive feedback information. In crayfish walking leg, many of these operations are performed directly by the motor neurons (MNs), which are connected monosynaptically by sensory afferents (CBTs) originating from a chordotonal organ that encodes vertical limb movements. An in vitro preparation of the crayfish CNS was used to investigate a new control mechanism exerted directly by motor neurons on the sensory inputs themselves. Paired intracellular recordings demonstrated that, in the absence of any presynaptic sensory firing, the spiking activity of a leg $\mathrm{MN}$ is able long-lastingly to enhance the efficacy of the CBT-MN synapses. Moreover, this effect is specific to the activated MN because no changes were induced at the afferent synapses of a neighboring silent MN. We report evidence that long-term potentiation (LTP) of the monosynaptic
\end{abstract}

EPSP involves a retrograde system of glutamate transmission from the postsynaptic MN, which induces the activation of a metabotropic glutamate receptor located presynaptically on the CBTs. We demonstrate that LTP at crayfish sensory-motor synapses results exclusively from the long-lasting enhancement of release of acetylcholine from presynaptic sensory afferent terminals, without inducing any modifications in postsynaptic MN properties. Our data indicate that this positive feedback control represents a functional mechanism that may play a key role in the auto-organization of sensory-motor networks.

Key words: glutamate; long-term potentiation; EPSP; crayfish; sensory-motor synapse; metabotropic glutamate receptor; quantal analysis
Although simply activating a central pattern generator can produce walking motor activities (Getting and Dekin, 1985; Grillner et al., 1991; Cazalets et al., 1995), it is now well accepted that the movement emerges from the processing and integration of sensory feedback information (Burrows, 1975; Rossignol et al., 1988; Viana Di Prisco et al., 1997). In walking animals, limb sensory receptors play a major role in the adaptation of posture and ongoing movements to external perturbations. In turn, the motor program can shape the incoming sensory inputs by different means such as presynaptic inhibition (Clarac et al., 1992; Rudomin et al., 1998) or centrally controlled neuromodulatory mechanisms (Bras et al., 1989; Skorupski, 1996). In the crayfish nervous system most of the sensory-motor integration is performed by the motor neurons (MNs) themselves (Le Ray and Cattaert, 1997; Le Ray et al., 1997). In the same way, various recent studies on vertebrate and invertebrate models have demonstrated the important role of MN properties in the production of the locomotor pattern (Arshavsky et al., 1993; Grillner et al.,

Received Aug. 31, 1998; revised Nov. 24, 1998; accepted Dec. 2, 1998.

This study was supported by the Centre National de la Recherche Scientifique. D.L. received funding from the Ministère de L'Education Nationale, de l'Enseignement Supérieur et de la Recherche (Allocation de Recherche 94-5-2302), followed by a short-term grant from the Fondation pour la Recherche Médicale. We thank Dr. J. Simmers for helpful comments on this manuscript and for improving the English version.

Correspondence should be addressed to Dr. D. Cattaert, Laboratoire de Neurobiologie des Réseaux, Centre National de la Recherche Scientifique-Unité Mixte de Recherche 5816, Université Bordeaux 1, Biologie Animale-Bât B2, Avenue des Facultés, 33405 Talence cedex, France.

Copyright (C) 1999 Society for Neuroscience $\quad 0270-6474 / 99 / 191473-11 \$ 05.00 / 0$
1995; Perrins and Roberts, 1995; Bertrand and Cazalets, 1998) or in the control of the incoming sensory signals (Cattaert and Le Ray, 1998).

In crayfish, glutamatergic MNs are accessed monosynaptically by the cholinergic sensory afferents originating from the coxobasipodite chordotonal organ $(\mathrm{CBCO})$ that encodes the vertical movements of the leg. In a previous work, Cattaert and Le Ray (1998) described a new presynaptic inhibition mechanism mediated by glutamate and exerted directly by the active MNs onto their presynaptic CBCO sensory terminals (CBTs).

In numerous models, neuronal electrical activity has been found to alter synaptic connections for long periods of time (Meyer, 1982; Frank, 1987; Alford et al., 1995). The long-lasting enhancement of synaptic efficacy, so called long-term potentiation (LTP), has been studied extensively in the mammalian brain structures (Gustafsson and Wigström, 1988; White et al., 1988; Zalutsky and Nicoll, 1990; Isaac et al., 1995). Long-term changes also have been described in various neuronal networks and especially in invertebrate motor systems such as in Aplysia (Castellucci et al., 1978; Dale et al., 1988) and the locust (Parker, 1995).

In the present study an in vitro preparation of the CNS of the crayfish was used to investigate the possible plastic changes that may occur at sensory-motor synapses involved in the sensory feedback control of leg movements. In this report we provide evidence that an active MN potentiates its own incoming sensory synapses in a long-lasting way. We demonstrate that the induction of this LTP is mediated by a spike-generated central release of glutamate from the postsynaptic MN, which activates a metabotropic glutamate receptor (mGluR) located presynaptically on the CBTs. Moreover, we show that LTP at crayfish sensory-motor synapses results from the long-lasting increase in probability of 
Figure 1. Demonstration of crayfish sensory-motor LTP. $A$, Drawing of in vitro preparation. G3, G4, and G5, Third, fourth, and fifth thoracic ganglia; Pro, Rem, Lev, Dep, motor nerves innervating promotor, remotor, levator, and depressor muscles, respectively; $C B n$, sensory nerve innervating the coxobasipodite chordotonal organ $(C B C O)$. Single or paired intracellular recordings ( $M E 1$ and $M E 2$ ) were made from a motor neuron $(M N)$ and $\mathrm{CBCO}$ sensory terminal $(C B T)$ within the fifth ganglion (see detail in right inset). B, Paired recordings of a CBT and MN were used to analyze the unitary monosynaptic EPSP produced in the $\mathrm{MN}$ in response to a CBT spike before (control) and after (postinduction) intracellular $10 \mathrm{~Hz}$ stimulation of the recorded MN (induction). After induction, the EPSP amplitude was increased dramatically. See superimposed raw data traces ( $t o p)$ and an average from 25 traces (middle). C, Time course of the mean amplitude of unitary EPSPs before and after MN intracellular stimulation (vertical gray bar), represented as a percentage of control (left) and maximum (right) values. Data were pooled from three representative experiments.

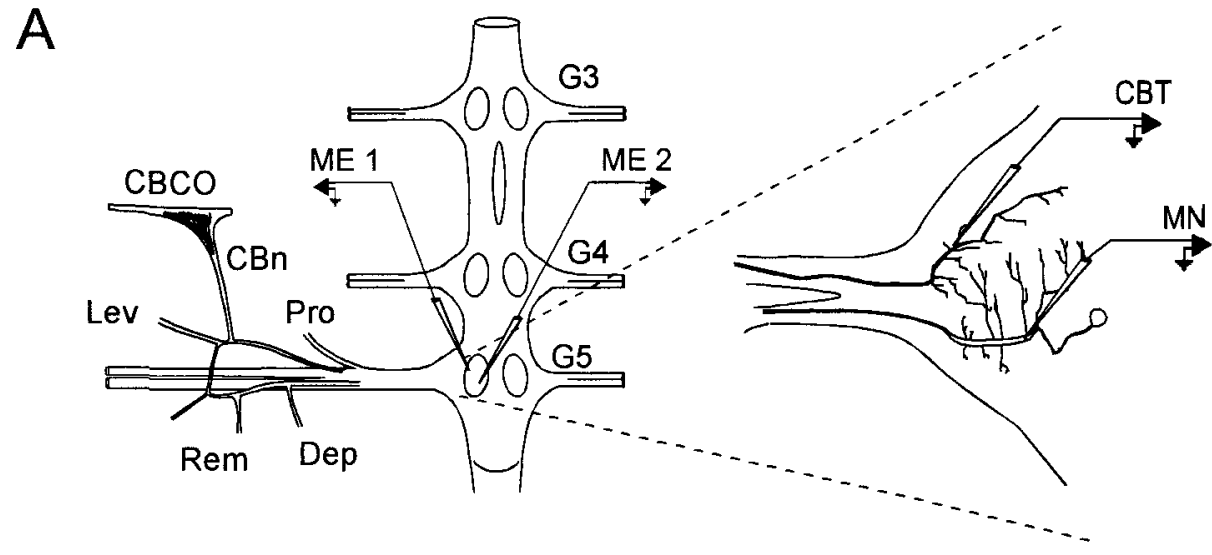

B

control
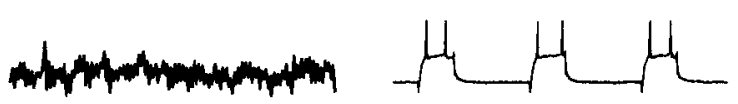

post-induction
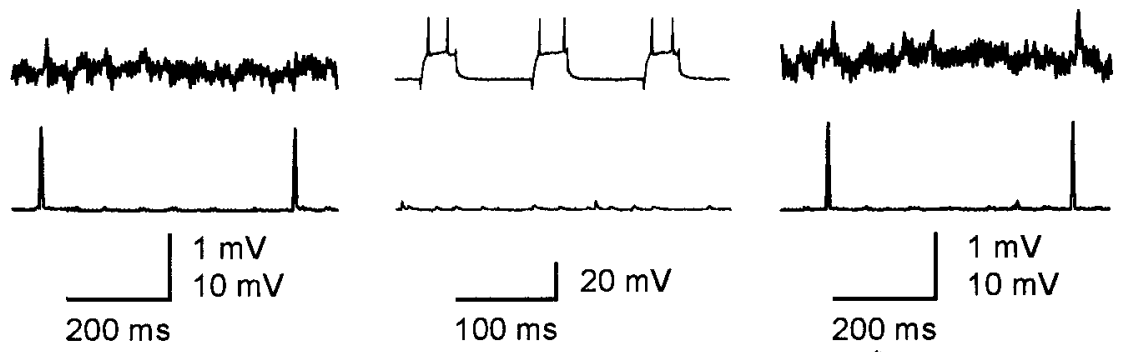

MN

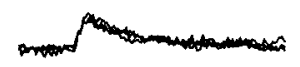

MN
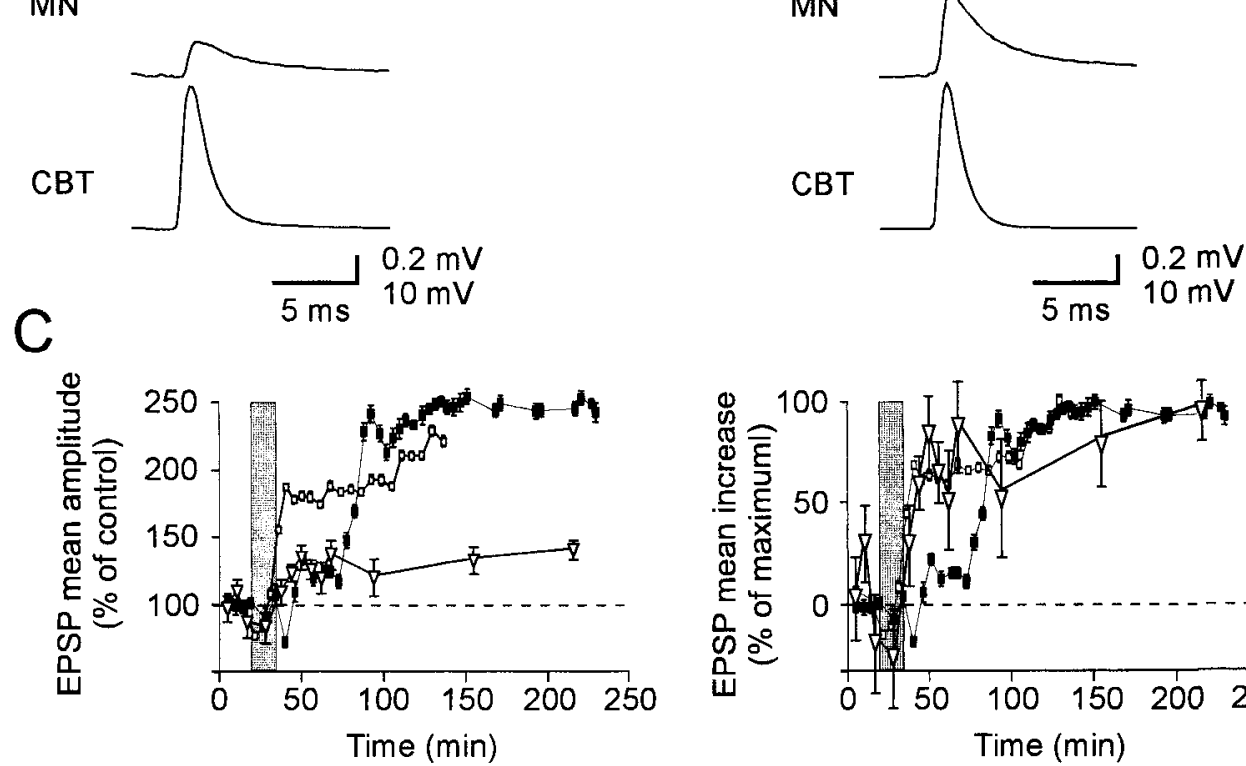

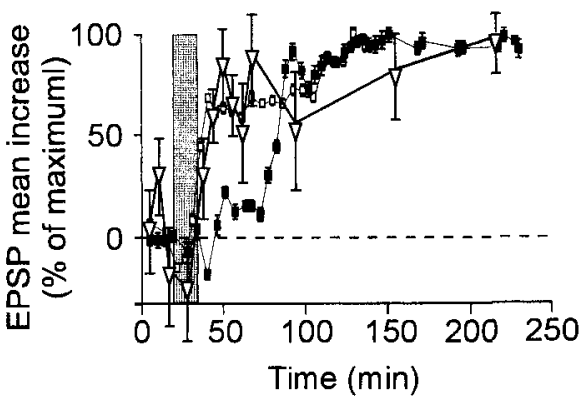

the release of acetylcholine from the CBTs. The functional significance of such a mechanism is discussed.

\section{MATERIALS AND METHODS}

Results are based on $>70$ single or paired intracellular recordings from MNs and CBTs (42 experiments) that were performed on adult male and female crayfish, Procambarus clarkii, weighing 25-30 gm. The animals, purchased from a commercial supplier (Chateau Garreau, Landes, France), were maintained in aquaria at $17-18^{\circ} \mathrm{C}$ and fed once a week.

Preparation. The in vitro preparation (see Fig. 1A) (Chrachri and Clarac, 1987) consisted of the last three thoracic ganglia and the motor nerves innervating the two proximal joints of the fifth leg: the two sets of antagonistic promotor/remotor (Pro/Rem) and levator/depressor (Lev/ Dep) motor nerves. The CBCO that encodes the vertical movements of the leg was dissected out, together with its sensory nerve (CBn). The preparation was pinned down dorsal side up in a Sylgard-covered Petri dish and superfused with oxygenated crayfish saline containing (in $\mathrm{mm}$ ) $195 \mathrm{NaCl}, 5 \mathrm{KCl}, 13 \mathrm{CaCl}_{2}$, and $2 \mathrm{MgCl}_{2}$. During experiments, divalent cation concentration was raised (34 $\mathrm{mMCaCl}_{2}$ and $6.4 \mathrm{mM} \mathrm{MgCl}_{2}$ ), with the sodium concentration reduced accordingly, to increase the threshold for spiking of the cells and thus reduce the efficacy of the polysynaptic pathways (Berry and Pentreath, 1976). Note that, in control experiments (i.e., in saline with a normal $\mathrm{Ca}^{2+}$ concentration), we have checked that LTP could still be induced (data not shown). All saline solutions were buffered with $3 \mathrm{~mm}$ HEPES and $\mathrm{pH}$-adjusted to 7.7 at $15^{\circ} \mathrm{C}$.

Recordings. Monopolar extracellular recordings and nerve stimulation were performed with platinum pin electrodes contacting the nerves, isolated from the bath with Vaseline, and directed to a four-channel 

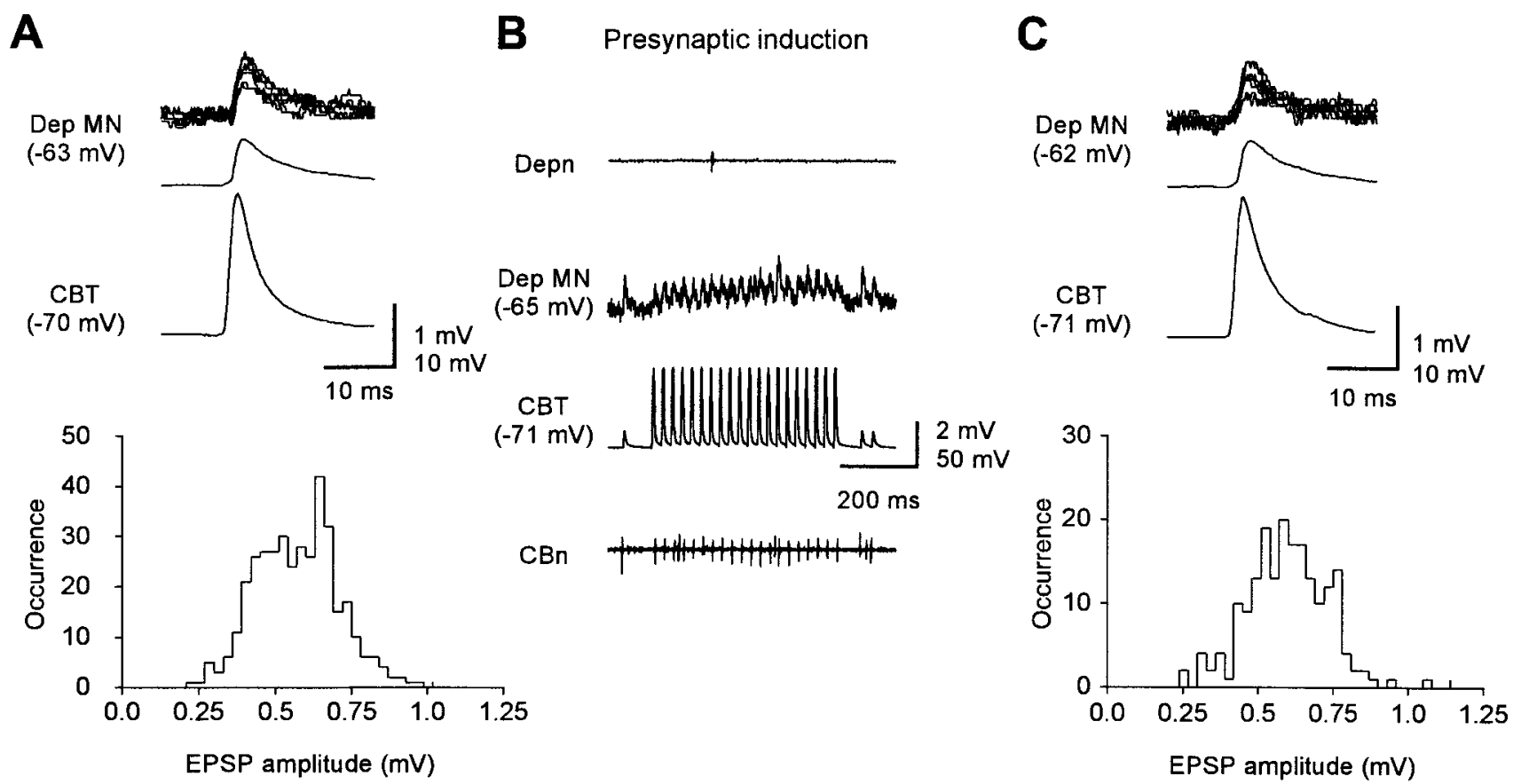

Figure 2. High-frequency presynaptic stimulation fails to induce LTP. $A$, Control unitary EPSPs were obtained by paired recording from a Dep MN (top trace, superimposed raw data; middle trace, average) and a presynaptic CBT (bottom trace, average from 25 consecutive raw data). The histogram displays the distribution (number of occurrences) of EPSP amplitudes. $B$, Induction protocol. The CBT was high-frequency-stimulated while the Dep MN remained silent. Depn and $C B n$, Extracellular neurograms of Dep motor nerve and CBCO sensory nerve, respectively; $D e p M N$ and $C B T$, paired intracellular recordings from a Dep MN and a CBT. $C$, After application of the induction protocol, no changes were observed in a single monosynaptic EPSP (same arrangements as in $A$ ).

differential AC amplifier (A-M Systems, Everett, WA). Single and paired intracellular recordings from MNs and CBTs were made with thin-walled glass microelectrodes filled with a potassium chloride solution $(3 \mathrm{M})$ and having a 25-30 M $\Omega$ resistance. The signals were amplified by an Axoclamp 2B (Axon Instruments, Foster City, CA). Intracellular current pulses delivered through the recording microelectrode and nerve stimulation were controlled by an eight-channel digital stimulator (A.M.P.I, Jerusalem, Israel). All physiological recordings were monitored on a four-channel digital oscilloscope (Yokogawa DL 1200, Tokyo, Japan) and on a digital tape recorder (BioLogics DTR 1802, Claix, France) and digitized on a PC-based computer via an analog-to-digital interface (Cambridge Electronic Device, CED 1401PLUS, Cambridge, UK). Intracellular and extracellular recordings were digitized at $5-10 \mathrm{kHz}$ and written to disk. Signals were analyzed with the CED programs SPIKE2 for spike sorting and SIGAVG for spike-triggered averaging.

Identification procedure for motoneurons and primary afferents. Contrary to mammals, terminal motor nerves of crayfish are composed exclusively of MNs, and the CBCO sensory nerve contains sensory fibers only (Bévengut et al., 1983). This anatomical feature allowed us to distinguish intracellularly recorded MNs from sensory axons. MNs and CBTs were identified after penetration with a microelectrode by the following procedure: (1) the spike evoked by electrical stimulation of its axon in the corresponding identified nerve could be recorded by the microelectrode; (2) there was a one-to-one correlation between intracellular spikes and corresponding extracellular nerve spikes during spontaneous activity; (3) intracellular injection of depolarizing current into the cell-evoked spikes correlated one-to-one with extracellular spikes recorded in the corresponding nerve.

LTP induction. To induce LTP at sensory-motor synapses, we applied either depolarizing current pulses injected via the intracellular recording microelectrode or extracellular stimulation of the motor nerve that carried the axon of the intracellularly recorded $\mathrm{MN}$ at a frequency of $<15 \mathrm{~Hz}$. In some experiments, intracellular negative current pulses $(-0.5 \mathrm{nA}, 300 \mathrm{msec}, 0.5 \mathrm{~Hz})$ were injected to monitor the MN input resistance throughout the experiment. In some experiments, LTP was induced by pharmacological substances that were applied by pressure ejection (50 msec, 2 bars) through a glass microelectrode (tip diameter, 5-10 $\mu \mathrm{m}$ ) with the use of a Picospritzer II (General Valve, Fairfield, NJ).
The microejections were delivered specifically onto the thin branches of CBTs within the ganglion.

Pharmacological studies. In some experiments the glutamate-pyruvate transaminase (GPT), an enzyme that rapidly degrades glutamate, was used. In some experiments glutamate, the glutamate ionotropic agonists NMDA and kainate (KA), and the glutamate metabotropic agonist trans-( \pm )-1-amino-1,3-cyclopentane-decarboxylate (ACPD) were pressureejected through ejection pipettes. The ability of various glutamate metabotropic antagonists ( $S$-4-carboxy-3-hydroxy-phenylglycine, 4C3HPG; $R, S$-amethyl-4-carboxyphenylglycine, MCPG; and 4-phosphonobutyrate, AP4) to block the glutamate-induced or electrically induced LTP, were tested. All chemicals were from Sigma (Saint-Quentin Fallavier, France), except 4C3HPG, which was from Tocris (Tocris Cookson, Bristol, UK).

Quantal and statistical analyses. The distribution histograms giving the statistical fluctuations in the EPSP amplitudes displayed regularly spaced peaks that easily could be assessed visually and were used to indicate the quantal transmitter release values. The mean quantal amplitude $q$ (i.e., the amplitude of the EPSP evoked by the release of one putative quantum) was taken to be the mean value $d V$ of the intervals between successive peaks in the histogram. The mean quantal content $m$ (i.e., the average number of quanta released by each action potential) was estimated indirectly as the mean EPSP amplitude/ $d V$. The validity of a simple binomial model and that of a Poisson model was tested on the experimental quantal distributions. According to the simple binomial model, the probability $p(0<p<1)$ of one quantum being released at each of the $n$ available releasing sites is uniform and stationary. The probability $p_{\mathrm{x}}$ of observing $x$ quanta is given by the binomial equation. In cases in which $p$ is very small (i.e., where $m$, the mean quantal content, is very small in comparison with $n$ ), the binomial distribution reduces to the Poisson distribution. In four of the five connections that were analyzed, the simple binomial model gave the best fit (significance level, $p<$ 0.05 ; $\chi^{2}$ test) (Del Castillo and Katz, 1954; Boyd and Martin, 1956).

Statistical analyses were performed by the GraphPad PRISM program (GraphPad Software, San Diego, CA). All results are given as mean \pm SEM. The significance of changes induced during LTP was measured by using a Student's unpaired $t$ test, excepted when the number of values was too small to test for a normal distribution. In this case a nonparametric Mann-Whitney test was used (see $R_{\text {in }}$ and $\tau$ at $120 \mathrm{~min}$ in Fig. 5A). 

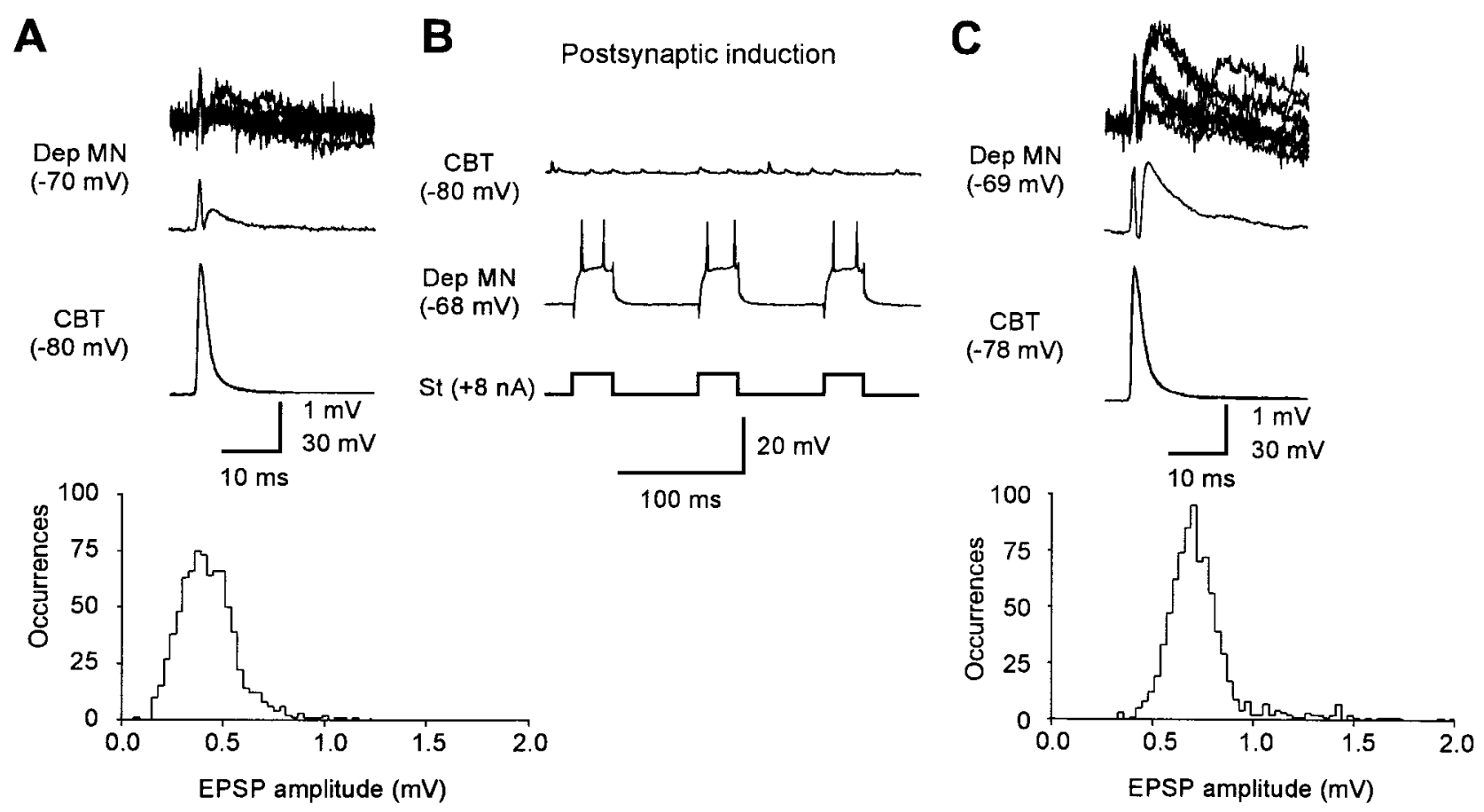

Figure 3. LTP induced uniquely by postsynaptic MN stimulation. $A$, Control unitary EPSPs were obtained during paired recording from a Dep MN and a presynaptic CBT (same arrangements as in Fig. $2 A$ ). The histogram presents the distribution (number of occurrences) of EPSP amplitudes. $B$, Induction protocol. The recorded Dep MN (middle trace) was stimulated intracellularly $(10 \mathrm{~Hz}$ ) while the presynaptic CBT (top trace, intracellular recording) remained silent. $C$, After the induction protocol the single EPSP amplitude was increased strongly. Note the quantal jumps that are visible in the raw data (same arrangements as in Fig. $2 C$ ).

\section{RESULTS}

\section{MN spiking activity induces LTP at the crayfish sensory-motor synapse}

Long-duration ( $>4 \mathrm{hr}$ ) paired recordings $(n=25)$ were obtained from MNs and presynaptic CBTs to study the time course of the monosynaptic EPSP before and after MN firing. Before activation the MN displayed small amplitude EPSPs in response to CBT spikes (Fig. 1B, control). Intracellular injection of depolarizing current pulses into the postsynaptic $\mathrm{MN}(10 \mathrm{~Hz}, 30 \mathrm{msec})$ with an intensity sufficient to elicit spikes was performed to induce firing in the absence of presynaptic activity (Fig. 1B, induction; in this case two spikes were elicited by each depolarizing current pulse). After this induction the MN displayed EPSPs for which the amplitude was increased dramatically from $0.16 \pm 0.12$ to $0.43 \pm 0.11 \mathrm{mV}$ (Fig. $1 B$; compare superimposed raw data and averaged traces of control and postinduction), whereas presynaptic spikes remained unchanged. The CBT spike amplitude was $63.422 \pm 0.045 \mathrm{mV}$ in control and $63.420 \pm 0.048$ $\mathrm{mV}$ after LTP induction $(n=247$; nonsignificantly different mean values), and half-spike width was $1.441 \pm 0.0001 \mathrm{msec}$ in control and $1.441 \pm 0.0001 \mathrm{msec}$ after LTP induction $(n=247$; nonsignificantly different mean values).

Figure $1 C$ displays the pooled plots of EPSP amplitudes during the course of three representative experiments. It shows that the short-term activation of a MN (vertical gray bar) was able to induce a strong and long-lasting $(>3 \mathrm{hr})$ increase in the amplitude of its monosynaptic sensory EPSP. Nevertheless, the left graph, displaying the amplitudes as percentages of control values, shows that, although each sensory-motor connection is able to produce LTP, the efficacy of this potentiation seems to depend on the activated synapse. The right graph, which displays the measure- ments as percentages of the maximum value, demonstrates that the time course of LTP induction was generally constant and rather slow (within the first 10 min after $\mathrm{MN}$ intracellular stimulation) between the different experiments. However, in very rare cases $(<5 \%)$ it appeared that some sensory-motor connections developed LTP in two phases, the first phase occurring within the same time scale as that generally observed, with the second phase occurring much later (within the next hour; see filled squares in Fig. $1 C)$.

\section{Only postsynaptic activity is required to induce LTP at the crayfish sensory-motor synapse}

Paired recordings were performed from MNs and presynaptic CBTs to study the roles of these elements in the LTP induction at the sensory-motor synapse. In some experiments $(n=10)$ only the presynaptic CBT was stimulated intracellularly, whereas in other experiments $(n=25)$ only the postsynaptic MN was activated by suprathreshold depolarizing current pulses. In both kinds of experiments the monosynaptic EPSPs were recorded for long periods of time before and after the intracellular stimulation.

As shown in Figure 2, presynaptic activation alone always failed to induce an increase in the monosynaptic EPSP amplitude. The presynaptic activation was mimicked by high-frequency (tetanizing stimulation, up to $100 \mathrm{~Hz}$ ) intracellular injection of suprathreshold depolarizing current pulses within the presynaptic CBT, in the absence of postsynaptic activity (as shown by the absence of extracellular spikes in the recorded $\mathrm{MN}$ as well as on the Dep neurogram; Fig. $2 B$ ). Before the presynaptic activation (Fig. 2A), single EPSP amplitudes ranged from 0.21 to $1.02 \mathrm{mV}$, whereas after application of the induction protocol (Fig. $2 C$ ), the EPSP amplitudes ranged from 0.24 to $1.13 \mathrm{mV}$. The distribution 
A

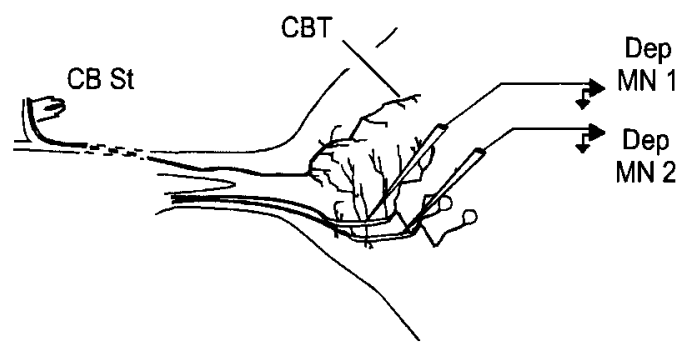

B

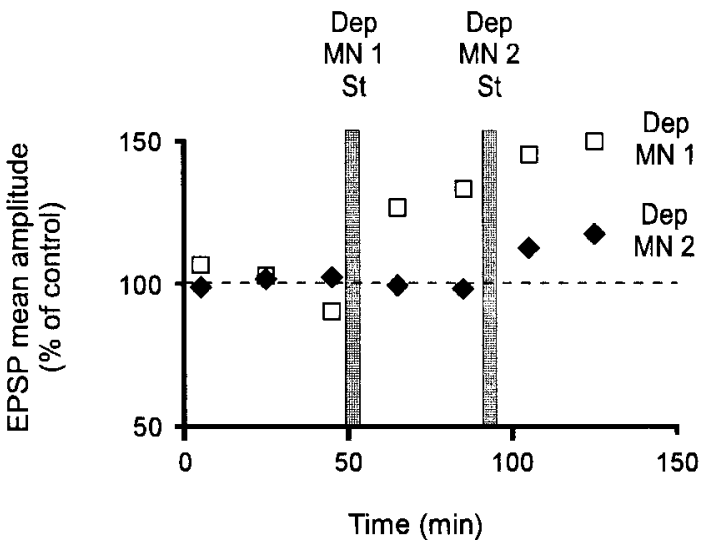

Figure 4. LTP induction is specific to the activated MN. $A$, Drawing of the recording protocol. Two Dep MNs were recorded simultaneously while sensory EPSPs were elicited by CB nerve extracellular stimulation $(C B S t)$. B, Time course of EPSP mean amplitude recorded in both Dep MNs. The intracellular stimulation of the first MN (Dep MN 1 St) induced only the potentiation of its own EPSPs $(\square)$. EPSPs in the second MN were potentiated later, only after intracellular stimulation of this second MN (Dep MN $2 S t, \diamond)$.

histograms before (Fig. 2A) and after (Fig. 2C) the induction (Fig. $2 B$ ) displayed mean values that were nonsignificantly different $(0.61 \pm 0.31$ and $0.60 \pm 0.32 \mathrm{mV}$, respectively). The superimposed samples as well as the averaged traces also demonstrate that the induction protocol did not affect the EPSPs (compare traces in Fig. $2 A, C)$.

Figure 3 illustrates an experiment in which the postsynaptic $\mathrm{MN}$ was stimulated intracellularly in the absence of any presynaptic activity (Fig. 3B). Paired recordings of a CBT and a postsynaptic Dep MN were performed before (Fig. 3A) and after (Fig. $3 C)$ the induction protocol. The same analysis as performed in Figure 2 demonstrated that the single EPSP amplitudes were increased significantly (ranging from 0.07 to $1.23 \mathrm{mV}$ before and from 0.33 to $2 \mathrm{mV}$ after the induction protocol), and the distribution histograms were shifted to higher mean values (from $0.40 \pm 0.23$ to $0.71 \pm 0.20 \mathrm{mV}$ ). Compare also the raw data and averages in Figure 3, $A$ and $C$.

\section{LTP induction at the crayfish sensory-motor synapse is specific to the MN activated}

In five experiments, paired intracellular recordings were performed on two MNs of the same functional group. Figure 4 presents one such experiment in which monosynaptic EPSPs elicited by extracellular stimulation of the $\mathrm{CBn}$ were recorded simultaneously from two Dep MNs (Fig. 4A). Both Dep MNs then were activated sequentially by intracellular injection of suprathreshold depolarizing current pulses. The graph in Figure $4 B$ displays the time course of EPSP mean amplitude in both MNs throughout the experiment. Almost constant before MN activation, the EPSP mean amplitude increased considerably and longlastingly in the first Dep MN that was stimulated (Dep MN 1), whereas it remained unchanged in the second Dep MN (Dep MN 2). This lack of potentiation of the MN2 EPSPs was not attributable to an inability of the MN2 sensory-motor synapse to be potentiated, because after intracellular stimulation of Dep MN2 a significant increase in the monosynaptic EPSP recorded from Dep MN2 was observed (up to a $37 \%$ increase). Over the same time, MN1 continued to potentiate by a further $33 \%$.

\section{LTP induction at the crayfish sensory-motor synapse occurs at the presynaptic site}

To analyze the postsynaptic effects of LTP, we performed experiments $(n=20)$ in which a single intracellular recording was performed from a MN (Fig. $5 A$ ), and monosynaptic EPSPs were elicited by extracellular stimulation of the CBn. Extracellular stimulation of the motor nerve (Dep $n S t)$ and antidromic invasion of the recorded MN then were used to induce LTP. The input resistance $\left(R_{\mathrm{in}}\right)$ and membrane potential $\left(V_{\mathrm{m}}\right)$ of the recorded Dep MN, as well as the amplitude and decay time constant $(\tau)$, of the EPSPs were measured throughout the experiment. The results demonstrated that LTP induction did not affect membrane properties $\left(R_{\mathrm{in}}, V_{\mathrm{m}}\right.$, and $\left.\tau\right)$ of the recorded Dep MN (Fig. 5A). None of the $R_{\text {in }}$ and $\tau$ values was significantly different from the control values, as revealed by the Student's $t$ test for measures at 30,40 , and $80 \min (n=6$ for each) and by the nonparametric Mann-Whitney test for measurements at $120 \mathrm{~min}(n=3)$. These observations therefore suggest that LTP is not induced at the postsynaptic site in the MNs themselves.

Paired intracellular recordings then were performed from a Dep MN and a presynaptic CBT to analyze the quantal variations of the single monosynaptic EPSP amplitude (Fig. 5B). In the example presented, LTP was induced by antidromic stimulation of the Dep motor nerve. After the induction the monosynaptic EPSPs displayed a more than twofold increase in their amplitude. Quantal analyses were performed (1) before and (2) after the induction of LTP on single EPSP amplitudes $(n=800)$. They demonstrated that the increase in the amplitude resulted from the strong increase in the probability ( $p$ increased from 0.385 to 0.8 ) of release of neurotransmitter by the CBT, without any changes in the quantal size $(q=60 \mu \mathrm{V})$ or total number of quanta $(n=16)$. This result and the lack of effect of LTP on MN properties strongly suggest that LTP may be induced at the presynaptic site without the participation of postsynaptic mechanisms.

\section{Direct application of glutamate onto presynaptic CBTs induces LTP at the crayfish sensory-motor synapse}

The role of glutamate in LTP was demonstrated in experiments $(n=12)$ in which a MN was recorded intracellularly while monosynaptic EPSPs were elicited by extracellular stimulation of the $\mathrm{CBn}$. Glutamate was applied directly by pressure microejection in the vicinity of the CBCO sensory terminals within the ganglion (Fig. 6A). We verified that the recorded $\mathrm{MN}$ remained silent throughout these experiments (data not shown).

In response to $\mathrm{CBn}$ electrical stimulation the recorded $\mathrm{MN}$ (Lev $M N$ in the example presented in Fig. 6B) displayed EPSPs with very constant shape and amplitude in the control condition. After glutamate microejection the amplitude of the EPSP dramatically increased from $2.2 \pm 0.2$ to $4 \pm 0.8 \mathrm{mV}$. The pressure application of glutamate onto the CBTs thus induced a large and long-lasting increase in the monosynaptic EPSP amplitude. 
A

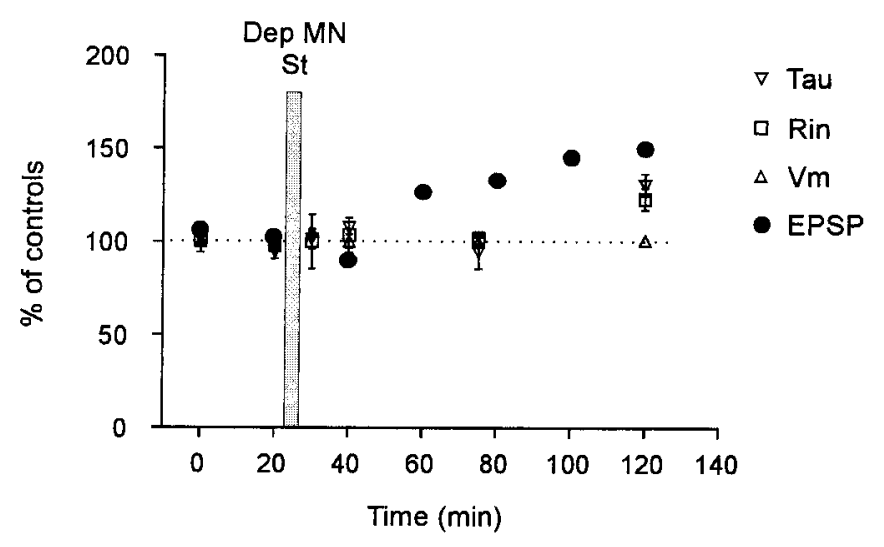

Figure 5. The LTP induction mechanism is presynaptic. $A, \mathrm{MN}$ intracellular stimulation (Dep $M N S t$ ) did not affect MN membrane properties, whereas it induced potentiation of the EPSP amplitude. $R_{\text {in }}$, Input resistance $(\square) ; V_{\mathrm{m}}$, membrane potential $(\Delta)$; Tau, EPSP decay time constant $(\nabla)$; EPSP, EPSP amplitude (๑). Error bars represent SE. $B$, Quantal analyses performed on 800 unitary monosynaptic EPSPs obtained by paired recording from a CBT and a Dep MN. The top graph displays the time course of EPSP amplitude throughout the experiment. LTP was induced by antidromically stimulating the Dep motor nerve (Dep $n$ St). The bottom graphs display the EPSP peak amplitude histograms before (left $t$ and after (right) LTP induction. Superimposed on histograms are the best fits, using simple binomial statistics and a Gaussian distribution of quantal amplitudes. $n$, Total number of quanta; $q$, quantal size; $p$, release probability.
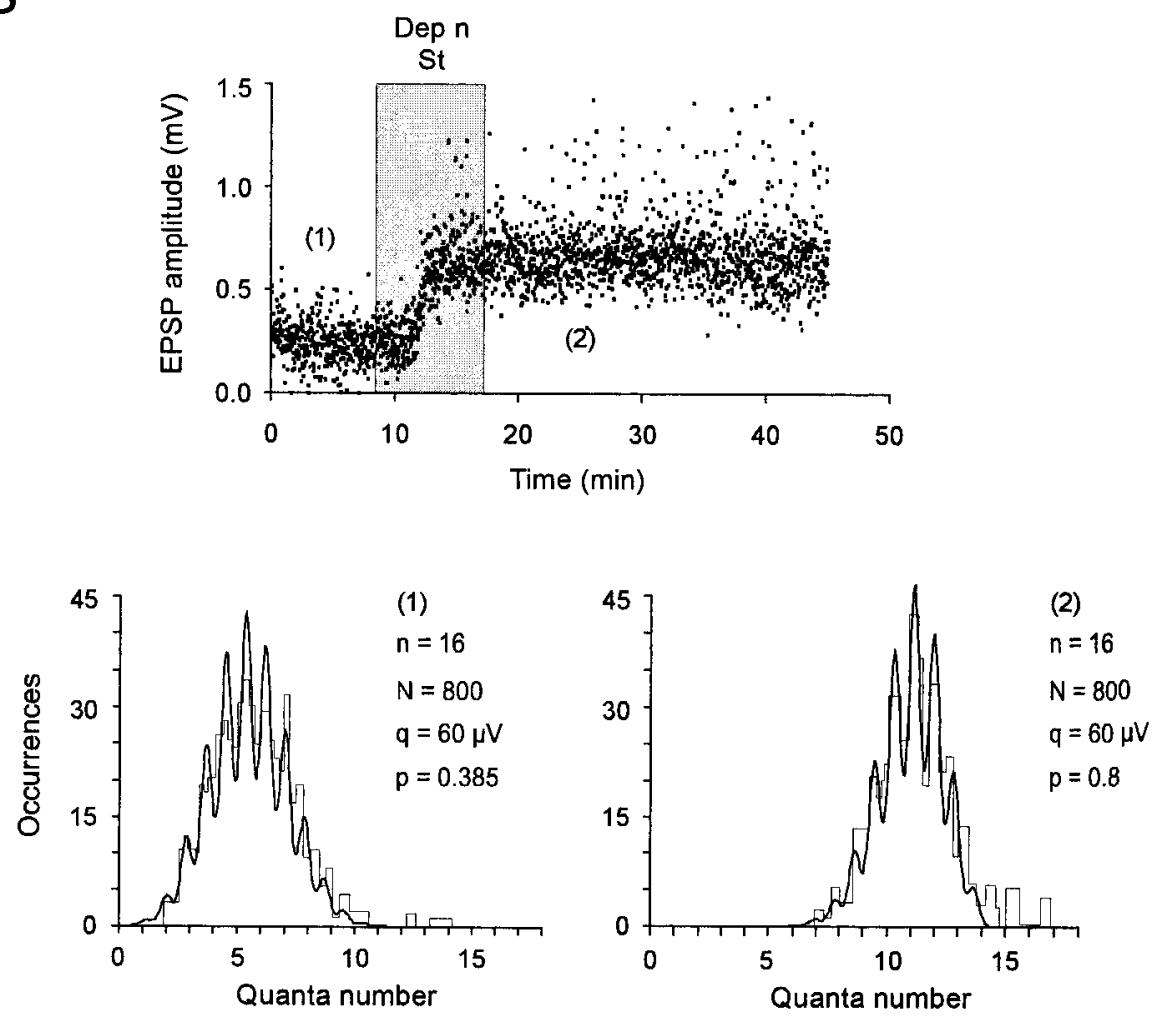

The lack of postsynaptic effect of the glutamate application was verified in five experiments by measuring the input resistance $\left(R_{\mathrm{in}}\right)$ of the recorded MN throughout the experiment. Figure $6 C$ displays pooled data obtained from five representative experiments. Figure $6 C_{1}$ displays the EPSP amplitude increase after glutamate microapplication (vertical black bar) as the percentage of control values. As was the case during $\mathrm{MN}$-induced potentiation, the efficacy of the exogenous glutamate-induced potentiation seemed to depend on the particular sensory-motor connection (compare with Fig. $1 C$, left). In contrast, there were no significant changes in the MN $R_{\text {in }}$. The graph in Figure $6 C_{2}$ displays the EPSP amplitude potentiation as a percentage of maximum value and demonstrates that glutamate-induced LTP occurred within the same time scale as that induced by MN intracellular activation (compare with Fig. 1C, right). Therefore, glutamate microapplication appeared to reproduce the presynaptic induction of LTP demonstrated above.

\section{LTP at the crayfish sensory-motor synapse involves central glutamate neurotransmission from the MN onto presynaptic CBTs}

GPT is an enzyme that rapidly degrades glutamate. In experiments $(n=7)$ in which only one MN was recorded intracellularly, we tested the effects of GPT $(30 \mathrm{U}$ in $100 \mathrm{ml})$ on the induction of LTP of the monosynaptic EPSPs elicited by electrical stimulation of the CBn (Fig. 7A).

As shown in Figure $7 B$, electrical stimulation of the $\mathrm{CBn}$ elicited small amplitude monosynaptic EPSPs $(1 \pm 0.10 \mathrm{mV}$, control) in the intracellularly recorded Lev MN. Bath perfusion of GPT prevented the increase in EPSP amplitude after application of the induction protocol by using intracellular suprathresh- 
A
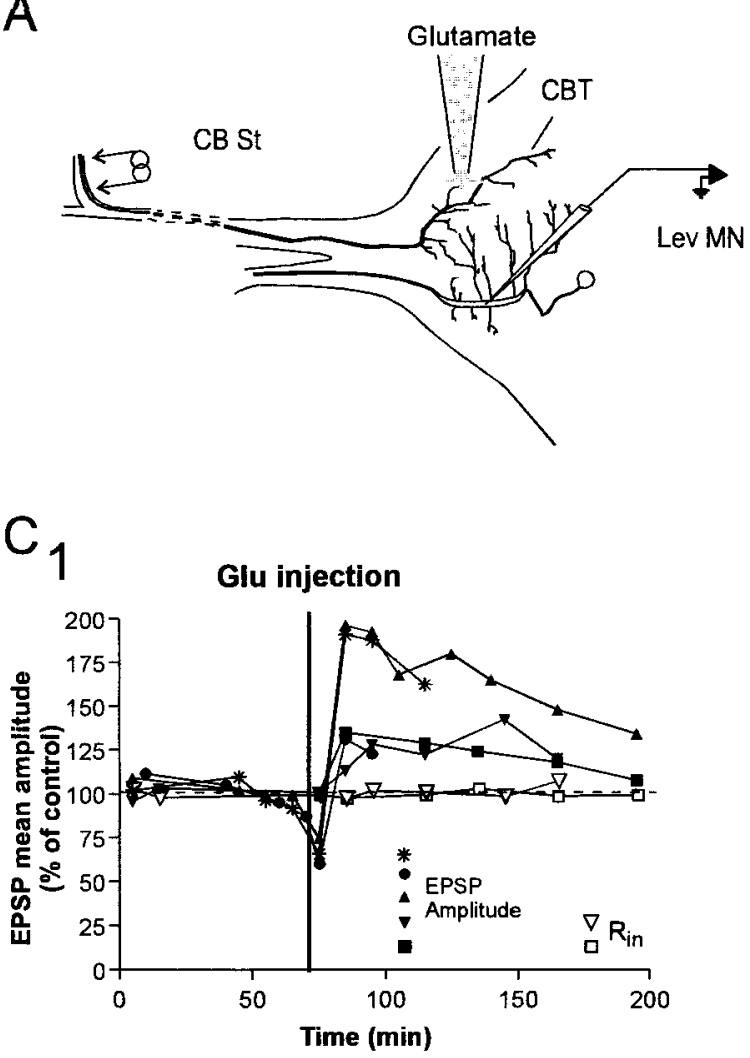

B
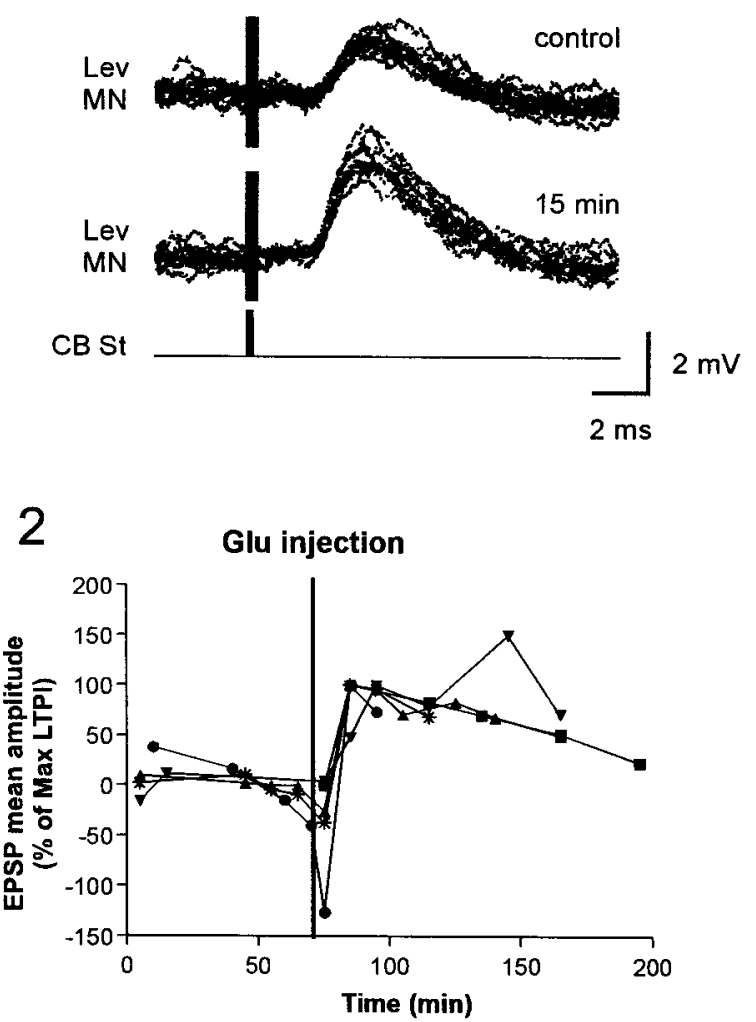

Figure 6. Glutamate microapplication induces LTP at sensory-motor synapse. A, Drawing of the experimental protocol. Monosynaptic EPSPs evoked by electrical sensory nerve stimulation $(C B S t)$ were recorded intracellularly from an Lev $M N$. Glutamate was pressure-applied to the neuropile in the vicinity of $C B T s$. B, Superimposed raw data of monosynaptic EPSPs recorded before (control) and after (15 min) glutamate microapplication. $C$, Time course of monosynaptic EPSP amplitudes (pooled from five representative experiments) and MN input resistance ( $R_{\mathrm{in}}$; pooled from two representative experiments) displayed as a percentage of control values $\left(C_{1}\right)$; the time course of EPSP amplitude increase is represented as a percentage of maximum values $\left(C_{2}\right)$. The vertical black bar represents glutamate microapplication.

old stimulation of the Lev MN ( $1 \pm 0.11$, postinduction 1$)$, whereas the same stimulation strongly increased the EPSP amplitude when GPT was removed from the bath $(2.8 \pm 0.4 \mathrm{mV}$, postinduction2). Comparable results also were obtained when LTP was induced by direct glutamate microapplication (data not shown).

GPT bath perfusion caused a reversible block of LTP induction. The graph in Figure $7 C$ displays the time course of the EPSP mean amplitude in response to LTP induction in the presence (horizontal black bars) or in the absence (horizontal white bar) of GPT in the perfusion bath. MN intracellular stimulation was used to induce LTP at three different times during the same experiment (vertical gray bars). First, in the presence of the enzyme, suprathreshold intracellular stimulation of the recorded Dep MN failed to induce any increase in the monosynaptic EPSP amplitude. Second, removing GPT from the perfusion bath allowed the development of the large (300\%) and long-lasting $(>5$ $\mathrm{hr}$ ) increase in the sensory-motor EPSP amplitude after MN intracellular activation. Returning to GPT perfusion did not affect the characteristics of the potentiated EPSP, which remained potentiated for $>3 \mathrm{hr}$ in the presence of the enzyme. Finally, the EPSP amplitude progressively decreased after $6 \mathrm{hr}$. At this time the presence of GPT prevented any new induction of LTP, and the EPSP amplitude went on decreasing until it reached its minimal value.

\section{Pharmacology of the glutamate-induced LTP at the crayfish sensory-motor synapse}

Various glutamate agonists (Fig. $8 A$ ) were substituted for glutamate in the ejection micropipette and ejected into the vicinity of the CBTs, where glutamate was able to induce potentiation of the monosynaptic sensory EPSP. The ionotropic glutamate receptor agonists NMDA $(n=4)$ or KA $(n=7)$ and the metabotropic glutamate receptor agonist ACPD $(n=8)$ were tested on EPSPs elicited by electrical stimulation of the CBn. Whenever tested before glutamate microapplication or after recovery from glutamate-induced LTP, none of the glutamate agonists that was ejected was capable of inducing any significant long-lasting change in the monosynaptic EPSP.

In view of the slowness of the LTP induction observed at crayfish sensory-motor synapses ( $\sim 10 \mathrm{~min}$; see Figs. $1 C, 6 C)$, we pursued the metabotropic analysis further, combining local glutamate microapplications with $\mathrm{mGluR}$ antagonist superfusion (Fig. $8 B$ ). In the presence of $4 \mathrm{C} 3 \mathrm{HPG}$ neither glutamate microejection (see graph in Fig. $8 B$ ) nor MN intracellular $(n=3)$ or antidromic stimulation $(n=3)$ resulted in LTP induction. By contrast, in control conditions such protocols were able to induce a significant long-lasting increase in EPSP amplitude. However, as shown by the histogram in Figure $8 B$, the other metabotropic glutamate antagonists tested, MCPG $(n=2)$ and AP4 $(n=2)$, were unable to prevent LTP induction. On the contrary, 4C3HPG 

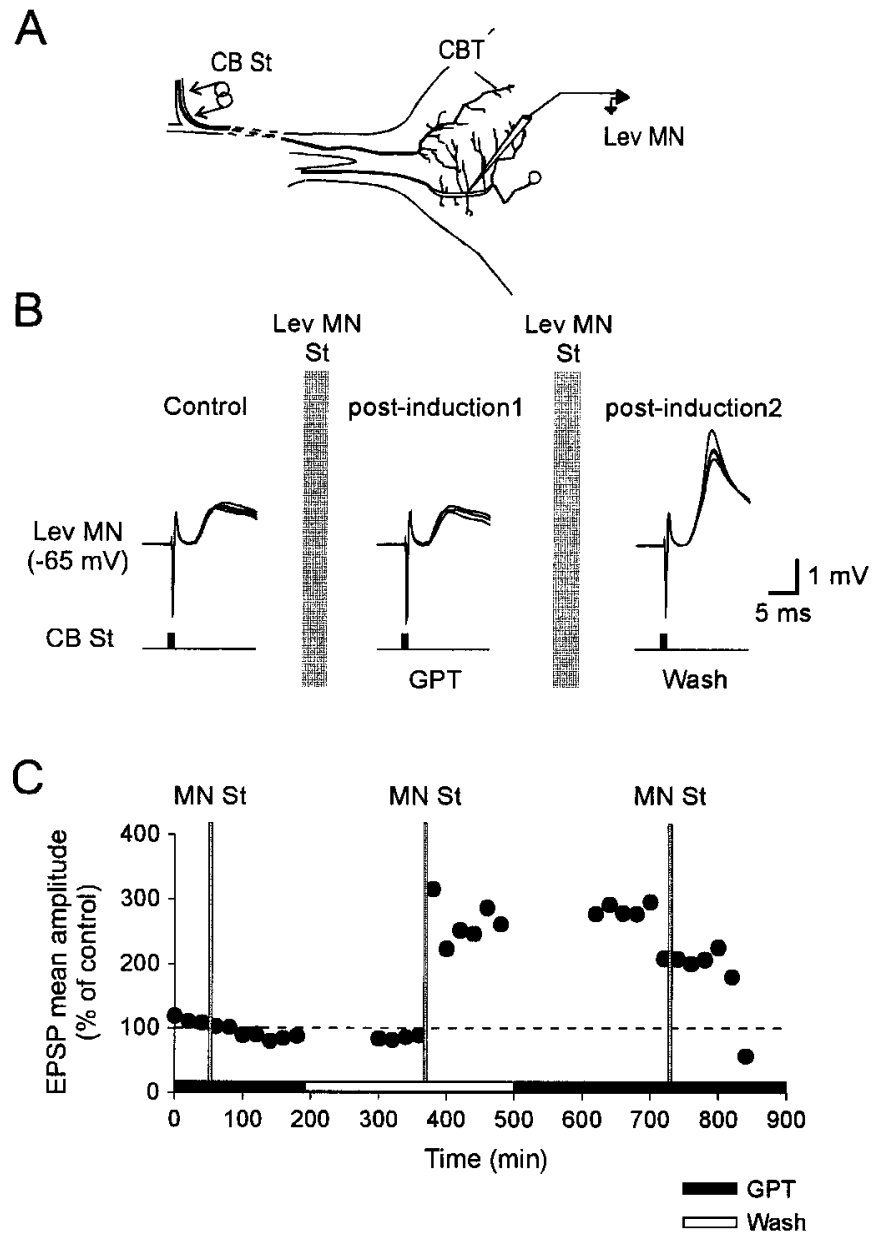

Figure 7. LTP is induced by central release of glutamate by the MN. $A$, Drawing of the recording protocol. Monosynaptic compound EPSPs evoked by electrical stimulation of the $\mathrm{CBCO}$ nerve $(C B S t)$ were recorded intracellularly from a $L e v M N$ in the presence or absence of GPT, an enzyme that rapidly degrades glutamate. $B$, Superimposed raw data of compound EPSPs demonstrating the complete inhibition by GPT perfusion (middle trace) and the recovery after wash (right trace) of the induction of LTP by the MN intracellular stimulation (Lev MN St). C, Time course of the EPSP mean amplitude obtained during a long-duration recording in the presence (black horizontal bars) and in the absence (white horizontal bar) of GPT.

always totally prevented sensory-motor LTP induction by glutamate microejection $(n=4)$, and this effect was reversible (see the wash bar in the histogram). These pharmacological results suggest that an invertebrate form of mGluR could mediate glutamateinduced LTP because it is prevented by $4 \mathrm{C} 3 \mathrm{HPG}$ perfusion but is insensitive to ACPD application.

\section{DISCUSSION}

\section{Crayfish sensory-motor synapses display LTP}

The present data clearly demonstrate that crayfish sensory-motor synapses are subject to plastic changes that long-lastingly enhance synaptic activity by a mechanism that involves the spiking activity of the postsynaptic $\mathrm{MN}$, but not that of the presynaptic sensory terminal. Moreover, we demonstrated that this LTP was mediated by glutamate (see Figs. 6, 8) and prevented by GPT superfusion (see Fig. 7). Therefore, we assume that the potentiation of the sensory-motor connection results from a direct retrograde action of the MN onto the CBTs. This assumption is reinforced by the fact that glutamate is the MN neurotransmitter (Van Harreveld, 1980) and that in all of our experiments routine perfusion of a high $\mathrm{Ca}^{2+} /$ high $\mathrm{Mg}^{2+}$ saline allowed only the monosynaptic connections to be effective (Berry and Pentreath, 1976).

\section{LTP at crayfish sensory-motor synapse originates from the MN and occurs at the presynaptic site}

As demonstrated in Figures 2 and 3, presynaptic activity is not required for the induction of LTP at the crayfish sensory-motor synapse. We showed that high-frequency $(30-100 \mathrm{~Hz})$ stimulation of the presynaptic afferent was unable to induce an increase in EPSP amplitude in the absence of postsynaptic discharge (see Fig. 2), even when the postsynaptic MN was depolarized to different subthreshold levels (data not shown). By contrast, in vertebrate and other invertebrate LTP models studied so far, activity-induced plasticity results from stimulation of the afferent pathway (Artola and Singer, 1987; Gustafsson and Wigström, 1988; Isaac et al., 1996). Therefore, in our model, LTP induction does not correspond to any previously reported classical associative (White et al., 1988) or nonassociative (Zalutsky and Nicoll, 1990) mechanisms of LTP induction. On the contrary, the sole firing of the postsynaptic $\mathrm{MN}$ in the absence of presynaptic activity (see Fig. 3) is sufficient to induce LTP at the crayfish sensory-motor synapse. In CA1 pyramidal cells, Neveu and Zucker (1996) have described long-lasting changes in synaptic efficacy that were induced without any presynaptic activity, by the photolysis of a caged $\mathrm{Ca}^{2+}$ compound that artificially elevated the postsynaptic intracellular $\left[\mathrm{Ca}^{2+}\right]$. Their results indicate that, at the Schaffer collateral-CA1 neuron synapse, LTP induction originates from the postsynaptic cell. Nevertheless, in normal conditions the increase in postsynaptic intracellular $\left[\mathrm{Ca}^{2+}\right]$ probably would involve the activation of glutamate NMDA receptors located at the synaptic site. It is likely, therefore, that the presynaptic Schaffer collateral plays a major role in the LTP induction. In crayfish sensory-motor LTP it appears that the presynaptic afferent does not play any significant role in the actual induction of the phenomenon. This perhaps is not surprising because the firing of a previously resting $\mathrm{MN}$ is driven by the central pattern generator itself. Because LTP of the sensory-motor synapses is induced by the sole firing activity of the MN, this plasticity thus may result from a natural induction mechanism and therefore may have an important functional significance (discussed below).

The observation of a lack of long-term modifications in the stimulated MN (see Figs. $5 A, 6 C$ ) and of the large increase in the probability of the presynaptic neurotransmitter release after LTP induction (see Fig. 5B) strongly suggests that the plastic changes occur exclusively in presynaptic sensory terminals (Kullmann and Nicoll, 1992). In hippocampus, Isaac and colleagues $(1995,1996)$ observed a similar increase in release probability and suggested that LTP could result from the activation of previously silent synapses (i.e., the activation of previously silent postsynaptic receptors; Isaac et al., 1995). Nevertheless, the observed concomitant increase in quantal size strongly suggests the involvement of the postsynaptic neuron (Isaac et al., 1996).

Interestingly, LTP induction in crayfish involves the activation of a mGluR located presynaptically on the CBT. Although an invertebrate mGluR has been cloned in Drosophila (Parmentier et al., 1996), this is the first time the role of mGluRs has been documented in an invertebrate neural network. Although mGluRs also are involved in synaptic plasticity in vertebrates (Bliss and Collingridge, 1993; Riedel et al., 1995), the LTP occurring at crayfish synapses constitutes an original strength 
A

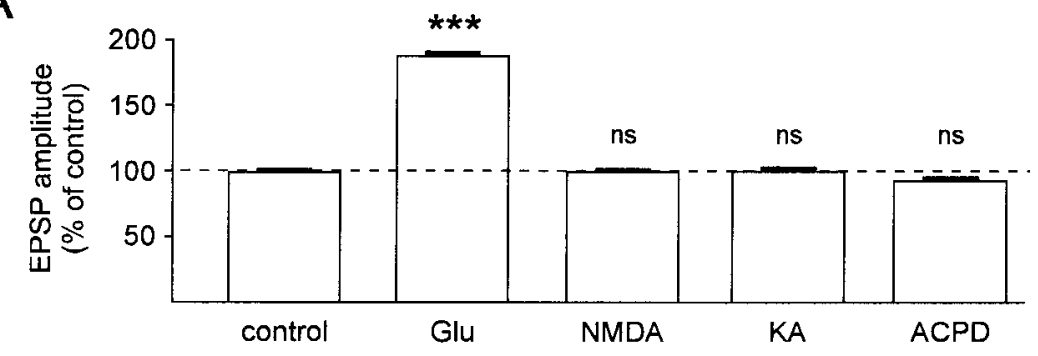

B
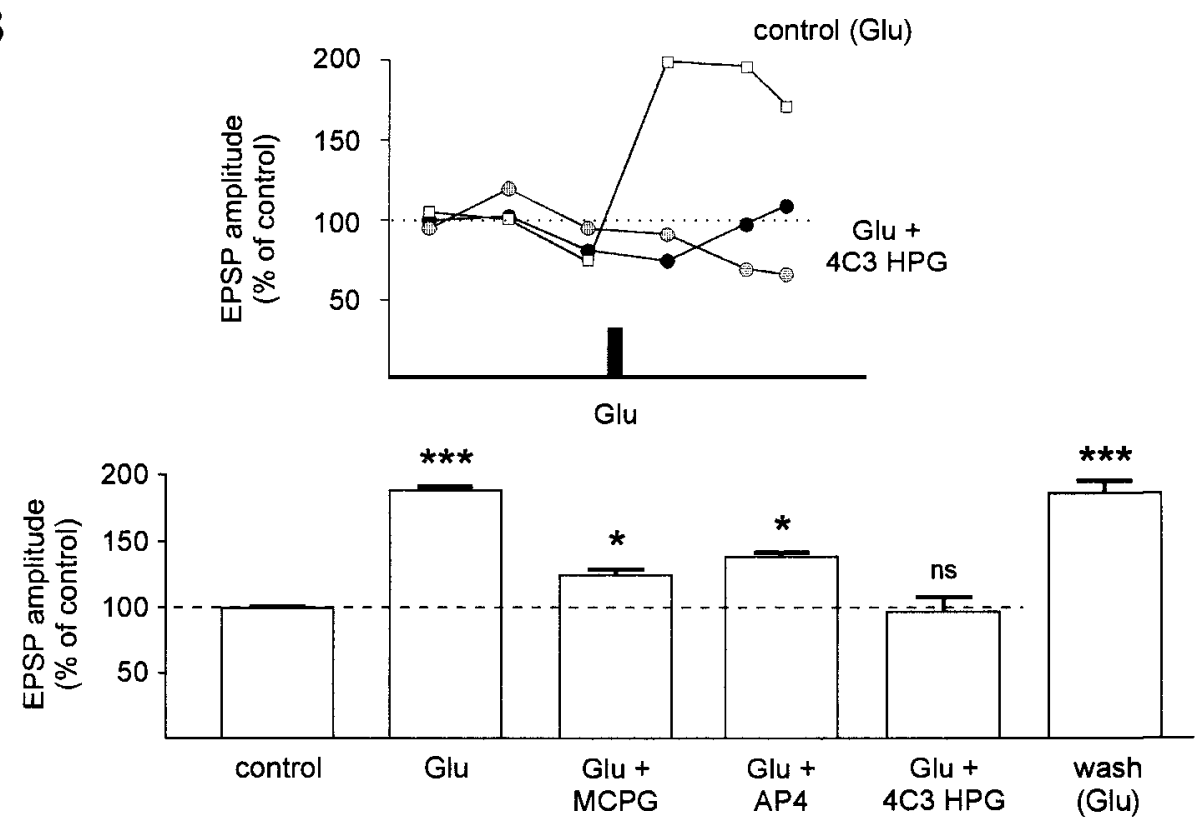

Figure 8. Pharmacology of glutamateinduced LTP. $A$, None of the glutamate agonists substituted for glutamate in the pressure ejection pipette was able to induce LTP of the monosynaptic EPSP elicited by extracellular stimulation of the $\mathrm{CBCO}$ nerve. Two ionotropic glutamate agonists, NMDA and kainate $(K A)$ and one metabotropic glutamate agonist, ACPD, were tested. $B, \mathrm{Al}-$ though the metabotropic glutamate antagonists MCPG and AP4 were unable to prevent LTP induction when they were added in the perfusion bath, 4C3HPG caused a complete and reversible (wash) blockade of the LTP induction by glutamate ejection. This indicates that a metabotropic form of glutamate receptor may mediate LTP induction. ${ }^{* * *} p<0.001 ;{ }^{*} p<0.05 ; n s$, nonsignificant. control mechanism, because its origin is purely postsynaptic whereas its effects are purely presynaptic. This contrasts strikingly with the studies performed in the Schaffer collateral-CA1 pyramidal cell system of vertebrates. In this model, LTP induction seems to result from the activation of the presynaptic afferent (the Schaffer collateral) concomitantly with the depolarization of the postsynaptic CA1 neuron (Nicoll et al., 1988; White et al., 1988). Moreover, several authors reported that the intracellular stimulation of the postsynaptic CA1 cell induces only an activitydependent depression of cell firing (Madison and Nicoll, 1984; Borde et al., 1995). In contrast, intracellular stimulation of the crayfish MN did not have any effect on the MN activated but enhanced its input synapses via a long-lasting facilitation of neurotransmitter release from presynaptic afferents.

\section{Functional significance}

The LTP mechanism described here could be involved in the organization of "sensory-motor network" function according to locomotor requirements. This notion is supported by the three following observations:

- Crayfish thoracic and abdominal ganglia MNs have been reported to be arranged in functional groups in which the MNs always have the same physiological properties and serve the same behavioral function (Faulkes and Paul, 1997; Sherff and Mulloney, 1997). However, the long-term positive feedback described here is specific to the MN activated (see Fig. 4).

- Previous studies on both vertebrate and invertebrate models put forward the idea that LTP induction may require highfrequency discharge of the participating neurons (Artola and Singer, 1987; Parker, 1995; Bao et al., 1997). However, the intracellular or extracellular stimulation frequencies used in our experiments never exceeded $15 \mathrm{~Hz}$, which corresponds to the low physiological spiking frequencies observed during locomotor behavior. Therefore, LTP induction in crayfish can be caused by "normal" neuronal discharges occurring during walking activities.

- It is also noticeable that it was never possible to potentiate further a given synaptic connection when it was potentiated already (data not shown). Moreover, LTP at the crayfish sensorymotor synapse only occurred when the preparation was previously kept quiet for a long time. As a consequence, before performing any single or paired intracellular recordings, we routinely waited at least $2 \mathrm{hr}$ to allow MNs to rest and thus for the sensory-motor synapses to operate at their lower levels of efficacy. In living animals such long silent period of MNs may occur, for example, when the animal is resting in its shelter.

Taken together, these observations suggest that LTP may always occur when the network is active and thus may constitute a gain control mechanism that reinforces the input synapses to specific MNs involved in locomotor activity.

This LTP mechanism appears to contrast with the previous description by Cattaert and Le Ray (1998) of the presynaptic inhibition of the $\mathrm{CBCO}$ produced by retrograde release of gluta- 
mate by postsynaptic target MNs. Nevertheless, both mechanisms require different levels of $\mathrm{MN}$ activity. MN glutamate-induced presynaptic inhibition requires the activity of the whole levator or depressor MN pool (Cattaert and Le Ray, 1998), whereas LTP can be elicited by the spiking activity $(<10 \mathrm{~Hz})$ of a single MN. Both mechanisms have very different time courses: presynaptic inhibition develops and disappears rapidly ( $<100 \mathrm{msec})$, whereas LTP needs a few minutes to develop and then persists for hours. Consequently, these two phenomena, although they are both produced by retrograde glutamatergic MN control, underlie different functions: the presynaptic inhibitory control may be involved in protecting MNs from saturation during ongoing motor activity (gain control mechanism), whereas the LTP mechanism could participate more in the activation of sensory inputs according to the requirements of the system.

These remarks are also relevant to the comparison of retrograde glutamate-induced LTP with presynaptic inhibition involving bursts of GABAergic primary afferent depolarizations (PADs) that are phase-locked with the locomotor rhythm (Cattaert et al., 1992). Here again, the time course of locomotionrelated GABAergic PADs is much faster than that of retrograde glutamate-induced LTP. Their functions are very different too: locomotion-related GABAergic PADs allow a phase-dependent regulation of negative feedback reflexes. Both mechanisms would not interfere because the retrograde glutamate-induced LTP mechanism does not require the activity of the primary afferent.

In conclusion, contrary to these phasic presynaptic control mechanisms, the retrograde glutamate-induced LTP is a longterm mechanism that is related to the composition of the sensory-motor network itself rather than to its immediate ongoing control; during the onset of a given motor activity, MNs and their afferents may be recruited as an ensemble like a single functional sensory-motor unit. Such a mechanism, which can be compared with the organizing properties of some interneurons within the stomatogastric ganglion of crustaceans (Meyrand et al., 1994), thus would invest in the $\mathrm{MN}$ a pivotal role in motor network auto-organization. The sensory-motor circuit in crayfish essentially is based on direct connections between sensory afferents and MNs, as is the case in the higher vertebrates. This mechanism therefore may not be limited to crayfish but also could occur in more evolved species such as vertebrates.

\section{REFERENCES}

Alford S, Zompa I, Dubuc R (1995) Long-term potentiation of glutamatergic pathways in the lamprey brainstem. J Neurosci 15:7528-7538.

Arshavsky YI, Orlovsky GN, Panchin YV, Roberts A, Soffe SR (1993) Neuronal control of swimming locomotion: analysis of the pteropod mollusc Clione and embryos of the amphibian Xenopus. Trends Neurosci 16:227-233.

Artola A, Singer W (1987) Long-term potentiation and NMDA receptors in rat visual cortex. Nature 30:649-652.

Bao JX, Kandel ER, Hawkins RD (1997) Involvement of pre- and postsynaptic mechanisms in posttetanic potentiation at Aplysia synapses. Science 275:969-973.

Berry MS, Pentreath VW (1976) Criteria for distinguishing between monosynaptic and polysynaptic transmission. Brain Res 105:1-20.

Bertrand S, Cazalets JR (1998) Postinhibitory rebound during locomotor-like activity in neonatal rat motoneurons in vitro. J Neurophysiol 79:342-351.

Bévengut M, Simmers AJ, Clarac F (1983) Central neuronal projections and neuromuscular organization of the basal region of the shore crab. J Comp Neurol 221:185-198.

Bliss TV, Collingridge GL (1993) A synaptic model of memory: longterm potentiation in the hippocampus. Nature 361:31-39.
Borde M, Cazalets JR, Buño W (1995) Activity-dependent response depression in rat hippocampal CA1 pyramidal neurons in vitro. J Neurophysiol 74:1714-1729.

Boyd IA, Martin AR (1956) The end-plate potential in mammalian muscle. J Physiol (Lond) 132:74-91.

Bras H, Cavallari P, Jankowska E, McCrea D (1989) Comparison of effects of monoamines on transmission in spinal pathways from group I and II muscle afferents in the cat. Exp Brain Res 76:27-37.

Burrows M (1975) Monosynaptic connections between wing stretch receptors and flight motoneurones in the locust. J Exp Biol 62:189-219.

Castellucci VF, Carew TJ, Kandel ER (1978) Cellular analysis of longterm habituation of the gill withdrawal reflex of Aplysia californica. Science 202:1306-1308.

Cattaert D, Le Ray D (1998) Direct glutamate-mediated presynaptic inhibition of sensory afferents by the postsynaptic motor neurons. Eur J Neurosci 10:3737-3746.

Cattaert D, El Manira A, Clarac F (1992) Direct evidence for presynaptic inhibitory mechanisms in crayfish afferents. J Neurophysiol 67: 610-624.

Cazalets JR, Borde M, Clarac F (1995) Localization and organization of the central pattern generator for hindlimb locomotion in newborn rat. J Neurosci 15:4943-4951.

Chrachri A, Clarac F (1987) Induction of rhythmic activity in motor neurons and interneurons of crayfish thoracic ganglia by cholinergic agonists. Neurosci Lett 77:49-54.

Clarac F, El Manira A, Cattaert D (1992) Presynaptic control as a mechanism of sensory-motor integration. Curr Opin Neurobiol 2:764-769.

Dale N, Schacher S, Kandel ER (1988) Long-term facilitation in Aplysia involves increase in transmitter release. Science 239:282-285.

Del Castillo J, Katz B (1954) Quantal components of the end-plate potential. J Physiol (Lond) 124:560-573.

Faulkes Z, Paul DH (1997) A map of distal leg motor neurons in the thoracic ganglia of four decapod crustacean species. Brain Behav Evol 49:162-178.

Frank E (1987) The influence of neuronal activity on patterns of synaptic connections. Trends Neurosci 10:188-190.

Getting PA, Dekin MS (1985) Mechanisms of pattern generation underlying swimming in Tritonia. IV. Gating of central pattern generator. J Neurophysiol 53:466-480.

Grillner S, Wallen P, Brodin L, Lansner A (1991) Neural network generating locomotor behavior in lamprey: circuitry, transmitters, membrane properties, and simulation. Annu Rev Neurosci 14:169-199.

Grillner S, Deliagina T, Ekëberg Ö, El Manira A, Hill RH, Lansner A, Orlovsky GN, Wallen P (1995) Neural networks that coordinate locomotion and body orientation in lamprey. Trends Neurosci 18:270-279.

Gustafsson B, Wigström H (1988) Physiological mechanisms underlying long-term potentiation. Trends Neurosci 11:156-162.

Isaac JT, Nicoll RA, Malenka RC (1995) Evidence for silent synapses: implications for the expression of LTP. Neuron 15:427-434.

Isaac JT, Hjelmstad GO, Nicoll RA, Malenka RC (1996) Long-term potentiation at single fiber inputs to hippocampal CA1 pyramidal cells. Proc Natl Acad Sci USA 93:8710-8715.

Kullmann DM, Nicoll RA (1992) Long-term potentiation is associated with increases in quantal content and quantal amplitude. Nature 357:240-244.

Le Ray D, Cattaert D (1997) Neural mechanisms of reflex reversal in coxo-basipodite depressor motor neurons of the crayfish. J Neurophysiol 77:1963-1978.

Le Ray D, Clarac F, Cattaert D (1997) Functional analysis of the sensory-motor pathway of resistance reflex in crayfish. II. Integration of sensory inputs in motor neurons. J Neurophysiol 78:3144-3153.

Madison DV, Nicoll RA (1984) Control of the repetitive discharge of rat CA1 pyramidal neurones in vitro. J Physiol (Lond) 354:319-331.

Meyer RL (1982) Tetrodotoxin blocks the formation of ocular dominance columns in goldfish. Science 218:589-591.

Meyrand P, Simmers J, Moulins M (1994) Dynamic construction of a neural network from multiple pattern generators in the lobster stomatogastric nervous system. J Neurosci 14:630-644.

Neveu D, Zucker RS (1996) Long-lasting potentiation and depression without presynaptic activity. J Neurophysiol 75:2157-2160.

Nicoll RA, Kauer JA, Malenka RC (1988) The current excitement in 
long-term potentiation. Neuron 1:97-103.

Parker D (1995) Long-lasting potentiation of a direct central connection between identified motor neurons in the locust. Eur J Neurosci 7:1097-1106.

Parmentier ML, Pin JP, Bockaert J, Grau Y (1996) Cloning and functional expression of a Drosophila metabotropic glutamate receptor expressed in the embryonic CNS. J Neurosci 16:6687-6694.

Perrins R, Roberts A (1995) Cholinergic and electrical motoneuron-tomotoneuron synapses contribute to on-cycle during swimming in $\mathrm{Xe}$ nopus embryos. J Neurophysiol 73:1005-1012.

Riedel G, Casabona G, Reymann KG (1995) Inhibition of long-term potentiation in the dentate gyrus of freely moving rats by the metabotropic glutamate receptor antagonist MCPG. J Neurosci 15:87-98.

Rossignol S, Lund JP, Drew T (1988) The role of sensory inputs in regulating patterns of rhythmical movements in higher vertebrates. In: Neural control of rhythmic movements in vertebrates (Cohen $\mathrm{AH}$, Rossignol S, Grillner S, eds), pp 201-283. New York: Wiley.
Rudomin P, Romo R, Mendel LM (1998) Presynaptic inhibition and neural control. New York: Oxford UP.

Sherff CM, Mulloney B (1997) Passive properties of swimmeret motor neurons. J Neurophysiol 78:92-102.

Skorupski P (1996) Octopamine induces steady-state reflex reversal in crayfish thoracic ganglia. J Neurophysiol 76:96-108.

Van Harreveld A (1980) L-Proline as a glutamate antagonist at a crustacean neuromuscular junction. J Neurobiol 11:519-529.

Viana Di Prisco G, Pearlstein E, Robitaille R, Dubuc R (1997) Role of sensory-evoked NMDA plateau potentials in the initiation of locomotion. Science 278:1122-1125.

White G, Levy WB, Steward O (1988) Evidence that associative interactions between synapses during the induction of long-term potentiation occur within local dendritic domains. Proc Natl Acad Sci USA 85:2368-2372.

Zalutsky RA, Nicoll RA (1990) Comparison between two forms of long-term potentiation in single hippocampal neurons. Science 248: $1619-1624$. 